\title{
EDITORIAL
}

\section{Hacia la internacionalización de la ACE}

$\mathrm{E}$ l diseño y puesta en ejecución del plan estratégico a largo plazo para la Asociación Colombiana de Endocrinología , Diabetes y Metabolismo, ACE , contemplaba en uno de sus puntos, avanzar en la internacionalización fortaleciendo los vínculos con Asociaciones de la talla de la AACE (American Association of Clinical Endocrinologists), The Endocrine Society y FELAEN (Federación Latinoamericana de Endocrinología), en este camino que venía siendo pausado y tentativo se nos presentó un hecho inesperado que nos brindó una gran oportunidad, ya que el Congreso Latinoamericano de Endocrinología del año 2018, organizado por FELAEN, cuya sede había sido asignada a la ciudad de Lima desde el año 2015, pero a la cual Perú resultó renunciando por motivos de fuerza mayor. Entonces nuestro anterior presidente el Dr. Pedro Nel Rueda, presentó la propuesta a la Asamblea de la ACE para asumir la realización de este congreso conjuntamente con nuestro séptimo Curso Internacional, y esta propuesta fue aprobada por mayoría de votos. Hemos iniciado desde la Junta Directiva una maratónica tarea para realizar dicho evento, logrando una convocatoria sin precedentes, entre los líderes académicos regionales que nos ha permitido consolidar un excelente programa académico en un tiempo record de tres meses.

El prestigio de nuestra Asociación ha traspasado las fronteras, esto es producto del trabajo de acercamiento a nuestros colegas endocrinólogos en otros países y de la confianza que crea en ellos la buena impresión que se llevan cuando aceptan participar en nuestros eventos, son repetidos los comentarios sobre la buena organización, el excelente nivel académico de las ponencias y la grata experiencia que viven en nuestro país; esto ha facilitado el trabajo de los líderes temáticos designados, quienes lograron la convocatoria de los mejores exponentes a nivel mundial, regional y local, lo que garantiza el éxito de nuestro próximo congreso. Tenemos además una oportunidad de oro para mostrar nuestro trabajo, por esto los invito especialmente a participar con sus trabajos de investigación en todas las áreas de la especialidad, que nos permitirá comparar casuísticas y comportamientos de las enfermedades endocrinas en nuestra región latinoamericana que de acuerdo con su demografía actual alberga a más de 600 millones de habitantes con multiplicidad étnica y social que representan un verdadero reto para mejorar sus condiciones de salud y vida.

Quiero desde este editorial invitarlos al tercer Congreso Latinoamericano de Endocrinología y séptimo Curso Internacional de la ACE que se celebrará en nuestra querida Cartagena de Indias, del 26 al 29 de abril de 2018 , estoy segura de que colmará todas sus expectativas, facilitará el contacto y la creación de vínculos con otras Asociaciones de Endocrinología de la región, en el desarrollo no solo de programas académicos y científicos, sino en la posibilidad de discutir y aprender de todas las experiencias regionales para la búsqueda de rutas y programas de atención, en beneficio de nuestros pacientes.

\section{Amanda Páez}

Presidente

Asociación Colombiana de Endocrinología, Diabetes y Metabolismo 